\title{
Convenience-based food purchase patterns: identification and associations with dietary quality, sociodemographic factors and attitudes
}

\author{
Jonas Peltner ${ }^{1}$ and Silke Thiele ${ }^{1,2, *}$ \\ ${ }^{1}$ Department of Food Economics and Consumption Studies, University of Kiel, Olshausenstraße 40, \\ 24098 Kiel, Germany: ${ }^{2}$ Institute of Food Economics, Fraunhoferstrasse 13, 24118 Kiel, Germany
}

Submitted 25 October 2016: Final revision received 26 September 2017: Accepted 18 0ctober 2017: First published online 27 November 2017

\begin{abstract}
Objective: The present study aimed to derive food purchase patterns considering the convenience level of foods. Associations between identified patterns and dietary quality were analysed, as well as household characteristics associated with the dietary patterns.

Design: A Convenience Food Classification Scheme (CFCS) was developed. After classifying basic food groups into the CFCS, the formed groups were used to apply a factor analysis to identify convenience-based food purchase patterns. For these patterns nutrient and energy densities were examined. Using regression analysis, associations between the adherence to the patterns and household characteristic and attitude variables were analysed.

Subjects: The study used representative German food purchase data from 2011. Approximately 12 million purchases of 13131 households were recorded in these data. Results: Three convenience-based patterns were identified: a low-convenience, a semi-convenience and a ready-to-eat food pattern. Tighter adherence to the semiconvenience pattern was shown to result in the lowest nutrient and highest energy densities. Important factors influencing adherence to the patterns were household size, presence of children and attitudes. Working full-time was negatively associated with adherence to the low-convenience pattern and positively with the ready-to-eat pattern.

Conclusions: Convenience foods were an important part of households' food baskets which in some cases led to lower nutritional quality. Therefore, it is important to offer convenience foods higher in nutrient density and lower in energy density. Interventions targeted on enhancing cooking skills could be an effective strategy to increase purchases of unprocessed foods, which, in turn, could also contribute to an improved diet quality.
\end{abstract}

Keywords: Convenience food Dietary patterns Factor analysis Diet quality
Convenience food consumption $\dagger$ in industrialized countries has increased steadily over recent decades ${ }^{(5)}$. A number of factors have contributed to this growth, including the growing number of single-person households and a smaller average household size ${ }^{(6,7)}$. Single households - especially single men - have been found to have a higher consumption of convenience foods than married couples or families with children ${ }^{(6,7)}$. An increased participation of females in the workforce has also

†Although convenience food is broadly discussed by researchers and the public, the meaning of 'convenience food' remains vague and the term is often used and interpreted differently ${ }^{(1-3)}$. In the present study a definition used in previous studies ${ }^{(3,4)}$ is applied: convenience foods are foods processed to minimize preparation time, as well as the physical and mental effort required for preparation for the household. contributed to the increasing consumption of convenience foods ${ }^{(8)}$. Furthermore, an unwillingness to cook meals from scratch ${ }^{(3)}$ has increased the demand for convenience foods. Candel, for example, found a negative relationship between convenience orientation and the consumption of self-prepared meals ${ }^{(3)}$. A lack of culinary skills was also found to be a predictor of convenience food consumption $^{(4)}$. While meeting the demands for convenience of modern Western societies, convenience foods are often rich in energy, fat, salt and sugar ${ }^{(9-11)}$. However, a combination of convenience foods of lower nutritional quality with healthier foods such as fruits and vegetables could possibly lead to an overall diet quality that meets or is close to nutritional recommendations. Hence, it is interesting to analyse the ways in which different types of 
convenience foods are combined by consumers, an approach known as food pattern analysis. A number of food pattern analyses have been carried out in recent years for different applications; for example, after patterns were identified, they were linked with a number of health outcomes $^{(12-16)}$, or the relationships between food patterns and socio-economic status as well as food patterns and nutrient status were examined ${ }^{(17,18)}$. However, none of these previous analyses focused explicitly on the convenience level of foods. The present study is the first to use food groups classified by their level of convenience as a basis for food purchase pattern analysis. To facilitate the analysis, the study made use of a representative data set of German food purchases in 2011, which recorded information about approximately 12 million food purchases from 13131 households. Using these data, each purchased food was classified by its degree of convenience. After identifying the food patterns, the nutrient profiles of the patterns were analysed and their associations with household characteristics and attitudes were examined.

\section{Materials and methods}

\section{Data and data preparation}

\section{Database}

The study made use of scanner data of 13131 representative German households. The data were collected in 2011 by the Gesellschaft für Konsumforschung (GfK; 'Association for Consumer Research'), a private market research organization. Households in the panel were recruited by GfK based on a two-stage quota sample. In the first stage, households were recruited based on quota for geographical areas, age, household size and nationality. In the second stage, the sample was adjusted using sampling weights, such as state, size of town, household size, age of the person in charge of the household, number of children in different age groups and nationality. Quotas were taken from the German micro census, an annual sample of $1 \%$ of the German population in which randomly selected households are obliged to participate. Households in the panel participate over multiple time periods; when a household leaves the panel a new household is recruited in compliance with the quotas.

The participating households were requested to document all their food purchases for at least a 10-month period per year.* To document their purchases, households scanned the food's barcode with an in-home scanning device. The bar code gives information about price (in Euros), quantity (in grams) and various product details of foods. Products without a barcode, such as fresh vegetables

*To ensure that only households who participated long enough for their purchases to reflect their usual shopping behaviour are included in the data set, all households with fewer than 300 purchases were excluded from our analysis. or fruits, had to be hand-keyed. In 2011, the participating households recorded a total of 12408473 food purchases including 6033 different food items. In addition, the data provide information about participating households' sociodemographic characteristics (e.g. age, education and income) and some attitudes of the person responsible for the household's food purchases. Once per year, the person was asked to complete a Likert-scale questionnaire including statements related to healthy eating, use of supplements and fortified foods, naturalness of foods and shopping behaviour. Examples of such statements are: 'We pay attention to a food's sugar content', 'We use vitamin and/or mineral supplements' and 'We don't buy genetically modified food'. A list of all statements used in the present study can be found in the online supplementary material, Supplemental Table 1.

Because the data contained no information about the nutritional values of the purchased foods, we linked this information to the data. For this purpose, the German food composition database (Bundeslebensmittelschlüssel version 3.01; BLS) was used, which gives information on 137 nutritional values of 14814 foods available in the German food market. Because the classification of food items in the BLS is often less precise than that used by the GfK, some GfK food items had to be aggregated. For example, whereas the GfK distinguishes between 168 different flavours and types of yoghurt, they had to be classified into four types captured by the BLS (fruit, cereal, natural, soya). Altogether, linking foods to the BLS resulted in the reduction of the number of products from 6033 to 1954 .

\section{Classifying food groups}

To conduct a factor analysis, the 1954 food items had to be aggregated into food groups. As the interest in the study was getting deeper insights into how people combine foods according to their convenience level, we conducted a literature review concerning existing convenience classification schemes but mostly found schemes that focused on the degree and purpose of food processing ${ }^{(5,19,20)}$. Food processing is defined as any processing that alters a food from its natural state and includes, for example, washing, cutting, pasteurizing, cooking, canning and freezing ${ }^{(21)}$. Such classifications, especially the NOVA classification $^{(19)}$, have been increasingly used in recent years to monitor the consumption of processed foods and to measure the impact of food processing on diet quality $^{(21-23)}$. However, using a classification scheme based on food processing is not suitable for the current analysis because it does not consider all aspects of convenience. Besides processing, convenience includes further criteria such as the amount of time needed for preparation before a food can be consumed ${ }^{(24-30)}$, the amount of culinary skills needed for preparation ${ }^{(29)}$, and the energy and attention a household has to use while preparing the food $^{(30)}$. Some studies consider the context in which a food is consumed (e.g. as a snack, a component of a meal 
Examples

\begin{tabular}{|c|c|}
\hline \multicolumn{2}{|c|}{ Convenience level I: raw foods and ingredients that require cooking or preparation } \\
\hline \multicolumn{2}{|l|}{ Purposes of use } \\
\hline Cla. Raw foods & Raw vegetables, fresh fish \\
\hline Clb. Ingredients & Salt, herbs, flour \\
\hline \multicolumn{2}{|c|}{$\begin{array}{l}\text { Convenience level II: industrially processed foods that need further processing steps in the household } \\
\text { Levels of culinary skills and time to prepare a meal }\end{array}$} \\
\hline \multicolumn{2}{|l|}{ Levels of culinary skills and time to prepare a meal } \\
\hline $\begin{array}{l}\text { Cllc. Defrosting, heating, cooking and/or adding of ingredients } \\
\text { (e.g. salt) or used as an ingredient }\end{array}$ & Frozen vegetables, canned fruits, bagged sal \\
\hline $\begin{array}{l}\text { Clld. Defrosting, heating, cooking and/or adding predefined } \\
\text { quantities of ingredients }\end{array}$ & Baking mixes, instant potato mash \\
\hline $\begin{array}{l}\text { Clle. Defrosting, heating and/or cooking, no further steps are } \\
\text { necessary (meal components) }\end{array}$ & Fish fingers, French fries \\
\hline \multicolumn{2}{|l|}{ Convenience level III: ready-made meals and ready-to-eat products } \\
\hline \multicolumn{2}{|l|}{ Context in which a food is consumed } \\
\hline CIllf. Ready-made meals & Frozen, chilled and canned main courses \\
\hline Clllg. Sweet and salty snacks, desserts & Chocolate, chips, yoghurt, ice cream \\
\hline Clllh. Other ready-to-eat products & Bread, cheese, sausages, ready-to-eat fruits \\
\hline
\end{tabular}

or a complete meal) ${ }^{(1,24)}$, or a distinction between meal components such as vegetables, pasta and cooking ingredients (e.g. salt, herbs and spices) is made ${ }^{(19,26,27)}$. In economic studies a household's opportunity costs of time is often taken into account as a criterion for convenience $^{(24)}$. As there can be considerable variation in the degree of convenience in food groups of the same degree of processing, a classification based on convenience should not focus on the degree of processing alone ${ }^{(24)}$. This becomes obvious when grouping food products such as dried mashed potatoes and a ready-to-eat potato salad: as both products are highly processed, they would be classified into the same processing group; but considering the time and cooking skills needed for preparation, the dried mashed potatoes would be grouped into a lower convenience level than the ready-to-eat potato salad.

As none of the existing classifications used all aspects considered important for our analysis, we developed a new Convenience Food Classification Scheme (CFCS). This scheme includes the degree of processing, culinary skills required to transform the bought food into a meal, the time needed for meal preparation, the time needed after consumption (e.g. cleaning up and washing dishes) and the context in which a food or meal is consumed (e.g. snack or ready-made meal). Based on these criteria three convenience categories were defined: the first comprises raw foods and ingredients (CI), the second includes industrially processed foods that need further processing steps in the household (CII) and the third comprises ready-made meals and ready-to-eat products (CIII). Each of these groups has several subgroups used to allow different purposes of use (CIa, CIb), different levels of culinary skills as well as time to prepare a meal (CIIc-CIIe), and different contexts in which a food or meal is consumed (CIIIf-CIIIh). Beverages were excluded from the analysis because the concept of convenience does not apply to beverages. An overview of the classification scheme (CFCS) and some example foods are shown in Table 1. A more detailed list of example foods can be found in Table 2 . It should be noted that assigning food groups based on the level of convenience does not take a food's nutrient content into account. Hence, foods such as baby carrots and sausages can be part of the same food group as they are both ready-to-eat products.

\section{Statistical analyses}

\section{Identification of food patterns}

Food patterns were derived using exploratory factor analysis, which aims to achieve a reduction in the number of variables. By aggregating highly correlated variables and separating them from weaker correlated variables, exploratory factor analysis eases the interpretation of the data by revealing latent, underlying, unobservable factors. The unobservable common factors $\left(F_{1}, F_{2}, \ldots, F_{m}\right)$ and the unobservable unique factors $\left(U_{1}, U_{2}, \ldots, U_{n}\right)$ linearly reconstruct the original variables $\left(z_{j i}\right)$. Common factors are present in more than one variable of the set, whereas unique factors are present in only a single variable of set. The association between an original variable $z_{j}$ and the latent factors can be expressed as follows for a particular household $i^{(31)}$ :

$$
z_{j i}=a_{j 1} F_{1 i}+a_{j 2} F_{2 i}+\cdots+a_{j m} F_{m i}+a_{j} U_{j i},
$$

where $z_{j i}$ is food group $j$. The expression $a_{j i}$ is a linear pattern coefficient describing factor loadings that indicate how strongly the respective variables are weighted for each factor and the correlation between the variable and the factor. The model was analysed using the factor command in the statistical software package STATA SE version 13 for Windows.

The food groups included in the current analysis are listed in Table 2. All food groups were expressed as total grams purchased by a household. The factors were retained based on the criteria of eigenvalue $>1.0$ and a plot of the eigenvalues (scree plot). To streamline the 
Table 2 Convenience food groups used in the food pattern analysis

\begin{tabular}{|c|c|c|c|c|}
\hline \multirow{2}{*}{$\frac{\text { Convenience level I }}{\text { Cereals }}$} & \multicolumn{2}{|c|}{ Convenience level II } & \multicolumn{2}{|c|}{ Convenience level III } \\
\hline & & & & \\
\hline Cla Grain kernel, corn & Cllc & Chilled pasta, instant rice & Clllf & Chilled pasta and rice dishes \\
\hline \multirow{2}{*}{ Clb Flour } & Clld & Cake baking mixes & Clllg & Cake, cookies, muesli bars \\
\hline & Clle & Frozen bread for baking, frozen dumplings & Clllh & Bread, rolls \\
\hline \multicolumn{5}{|l|}{ Potatoes } \\
\hline \multirow[t]{3}{*}{ Cla Raw potatoes } & Clld & Dried mashed potatoes & Clllf & Canned potato soup \\
\hline & Clle & Frozen French fries, frozen stuffed potatoes & Clllg & Potato chips \\
\hline & & & Clllh & Potato salad \\
\hline \multicolumn{5}{|l|}{ Sugar \& Sweets } \\
\hline Clb Sugar, chocolate coating & Clld & Dessert powder, custard powder & $\begin{array}{l}\text { Clllg } \\
\text { Clllh }\end{array}$ & $\begin{array}{l}\text { Chocolate bars, tiramisu } \\
\text { Jam, honey }\end{array}$ \\
\hline \multicolumn{5}{|l|}{ Vegetables } \\
\hline \multirow[t]{2}{*}{ Cla Fresh vegetables } & Cllc & Frozen, canned or dried vegetables & Clllf & Canned vegetable soup \\
\hline & Clle & Frozen vegetables, seasoned & Clllh & Stuffed olives, stuffed peppers \\
\hline \multicolumn{5}{|l|}{ Fruits } \\
\hline Cla Fresh fruits & Cllc & Frozen, canned or dried fruits & Clllh & Ready-to-eat fruits \\
\hline \multicolumn{5}{|c|}{ - } \\
\hline \multirow[t]{2}{*}{ Cla Raw meat } & Cllc & Chilled or frozen meat, not seasoned & Clllf & Chilled, canned or frozen meat dishes \\
\hline & Clle & Hamburger patties, meat loafs & Clllh & Sausage, ham \\
\hline \multicolumn{5}{|l|}{ Fish } \\
\hline \multirow[t]{2}{*}{ Cla Fresh fish } & Cllc & Frozen fish or fish fillets, not seasoned & Clllf & Canned fish soup, frozen fish dinner \\
\hline & Clle & Fish fingers, floured or breaded frozen fish & Clllh & Fish salad, smoked salmon, tinned fish \\
\hline \multicolumn{5}{|c|}{ 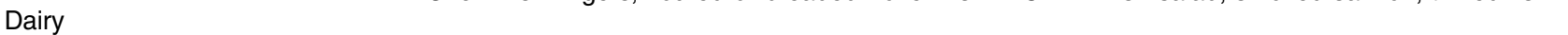 } \\
\hline \multirow[t]{3}{*}{ Clb Crème fraîche, sour cream } & & & Clllf & Canned cheese soup \\
\hline & & & Clllg & Fruit yoghurt, plain and flavoured yoghurt \\
\hline & & & Clllh & Cheese, tzatziki, herb curd \\
\hline \multicolumn{5}{|c|}{ 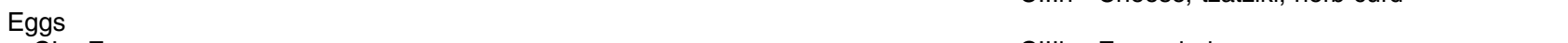 } \\
\hline Cla Eggs & & & Clllh & Egg salad \\
\hline \multicolumn{5}{|l|}{ Fats \& Oils } \\
\hline Clb Cooking fats, vegetable oils & & & Clllh & Butter, margarine, lard \\
\hline \multicolumn{5}{|l|}{ Other } \\
\hline Clb Salt, herbs, baking powder & Clld & Dehydrated sauce mixes & Clllh & Ketchup, custard, spiced sauces \\
\hline
\end{tabular}

interpretation of the results, a rotation method was used. First, we used the oblique rotation method, which allows factors to correlate. However, because the factor correlations ranged from 0.186 to 0.222 and this method is recommended for correlations higher than $0 \cdot 2^{(32)}$, it was decided to apply the orthogonal rotation method for the analysis. As conducted in previous studies, absolute factor loadings $\geq 0.4$ were considered significant ${ }^{(17,33)}$.

\section{Food patterns and diet quality}

Factor scores, which indicate the degree of the households' adherence to the respective food pattern, were calculated for each household using the regression $\operatorname{method}^{(34)}$ : the matrix of standardized quantities for each food group was multiplied by the matrix of factor loadings and the inverse of the variable correlation matrix. A high score indicated a stricter adherence to the pattern. These scores were divided into quintiles and the mean nutrient and energy densities of the purchased food baskets were calculated for each quintile. In addition, Pearson correlation coefficients between food pattern scores and energy and nutrient densities were calculated. The selected nutrients were those for which an unfavourable supply is noted in Germany and other industrialized countries ${ }^{(35)}$. Using regression analysis, trends were tested with the nutrient densities as dependent variables and the score quintile number as independent variable.

\section{Food patterns and bousehold characteristics}

To analyse the factors influencing the level of adherence to the respective food purchase pattern, multivariate regression analyses were carried out with the factor scores as the dependent variables and several household characteristics as independent variables. We selected those characteristics for which significant associations with convenience food consumption and dietary patterns were found in previous studies. These variables included household income ${ }^{(6,36)}$, number and composition of household members ${ }^{(8,37,38)}$, education level of the principal wage earner ${ }^{(6)}$, age of the person mainly responsible for the food purchases in the household ${ }^{(27)}$, price awareness $^{(6)}$ and working status of the person mainly responsible for the food purchases ${ }^{(3,4,39)}$. Also for health-related attitudes, significant associations with convenience food consumption were previously detected ${ }^{(38-41)}$. Because of the high number of attitude statements available in our data and because it could be assumed that many of them were closely linked, they were reduced using a factor analysis. Because of the ordinal nature of the statements, a non-linear principal component analysis was applied ${ }^{(42)}$.

\section{Results}

Table 3 shows the characteristics of the study households. Mean household size was 2.4. Of all participating 
Table 3 Definition and descriptive statistics of variables in a representative sample of 13131 German households with food purchase data from 2011

\begin{tabular}{|c|c|c|c|c|}
\hline & $n$ & Mean & SD & $\%$ \\
\hline Household income: net monthly income $(1000 €) \dagger$ & 13131 & $2 \cdot 261$ & 1.050 & \\
\hline No. of persons in the household & 13131 & 2.400 & 1.200 & \\
\hline Age of the person mainly responsible for food purchases in the household (years) & 13112 & 52.400 & $15 \cdot 500$ & \\
\hline Children aged $0-6$ years in the household & 13131 & & & 13.00 \\
\hline Children aged $7-13$ years in the household & 13115 & & & $16 \cdot 98$ \\
\hline Children aged $14-17$ years in the household & 13107 & & & 6.04 \\
\hline Single household, male & 13131 & & & $10 \cdot 30$ \\
\hline Single household, female & 13131 & & & $12 \cdot 80$ \\
\hline Lower education (principal wage earner)‡ & 13131 & & & $26 \cdot 40$ \\
\hline Higher education (principal wage earner)§ & 13131 & & & $30 \cdot 90$ \\
\hline Working part-time (person mainly responsible for food purchases) & 13131 & & & 23.20 \\
\hline Working full-time (person mainly responsible for food purchases) & 13131 & & & $26 \cdot 30$ \\
\hline High price awareness (person mainly responsible for food purchases) & 11643 & & & 42.40 \\
\hline
\end{tabular}

†Net monthly income reported in seventeen income intervals. The mean of each interval was chosen as the income of the respective household. Lowest interval: less than 499€. Highest interval: $5000 €$ or more.

$\ddagger$ Nine years of elementary school but no additional professional training (Hauptschule ohne Berufsausbildung).

§University degree (Fachhochschule/Hochschule/Staatsexamen).

households, $23 \cdot 1 \%$ were single households. Children of the youngest age group were present in $13.0 \%$ of the households. About $17 \%$ of the sample households had children aged between 7 and 13 years. Children aged 14 to 17 years were present in $6.0 \%$ of the participating households. In $26.3 \%$ of all households, the person responsible for the household's food purchases worked full-time and in $42.4 \%$ of all households this person stated that she or he had high price awareness.

\section{Identification of food purchase patterns}

Table 4 shows the results of the food pattern analysis. Three food patterns explaining $35.4 \%$ of the total variance in food purchases were derived. The first pattern was characterized by higher factor loadings $(>0.4)$ on all raw foods and ingredients (CI) and therefore was termed the 'low-convenience food pattern'. However, there were some readyto-eat food groups associated with the low-convenience food pattern, such as bread or cheese (category CIIIh). Those groups of the highest convenience category contain foods that are commonly bought as ready-to-eat products and are usually not crafted at home nowadays. The second pattern, termed the 'semi-convenience food pattern', had higher loadings for food groups that are processed in a way that they require only heating or cooking, such as chilled or frozen products (e.g. fish fingers and French fries; category CIIe) and some ready-made meals (category CIIIf). None of the raw food groups reached a factor loading of 0.4 or higher. The factor loadings for vegetables and fruits, regardless of their level of convenience, were low, but the loadings for sweet and salty snacks (category CIIIg) were comparatively high. The third pattern was characterized by higher factor loadings for ready-made meal products in the vegetable, potato and meat groups (category CIIIf) and for prepared delicatessen salads in the potato and fish groups (category CIIIh). This pattern was therefore termed the 'ready-to-eat food pattern'.

\section{Food patterns and diet quality}

The mean values and SE for the densities of selected nutrients per quintile of factor score are shown in Table 5. For reasons of clarity only the first, third and fifth quintiles are depicted in the table. Correlations of the three patterns with nutrients in the purchased foods are presented in the last column of Table 5. Households with higher food pattern scores (higher quintiles) in the low-convenience food pattern had higher nutrient densities for almost all listed micronutrients, except $\mathrm{Ca}, \mathrm{Mg}$ and $\mathrm{Fe}$. Although the nutrient densities for $\mathrm{Ca}$ and $\mathrm{Mg}$ were significantly negatively associated with the low-convenience food pattern score, the association for $\mathrm{Fe}$ did not reach statistical significance. The results of the correlation analysis confirmed these findings. The strongest correlations between the pattern scores and the selected micronutrients were those for vitamin D and vitamin C. Energy density was negatively associated with the food pattern scores for the lowconvenience pattern, which means that an increasing pattern score was associated with a lower, and therefore favourable, energy density. The P/S quotient (PUFA divided by SFA) was also negatively correlated with the food pattern score. Therefore, increasing adherence to the lowconvenience pattern resulted in purchasing a food basket with a worse fat composition. Percentage of energy from sugar and density of salt were both positively correlated with the low-convenience pattern score.

In the semi-convenience food pattern, the mean densities for all nutrients in the foods as purchased except vitamin E clearly declined with increasing pattern score quintile. These associations were confirmed by the correlation analysis. The strongest negative correlations were those for vitamin D, folate and vitamin C. Energy density was positively associated with food pattern scores, indicating that households with a higher adherence to the semi-convenience food pattern consumed a higher mean energy density. The association between the $\mathrm{P} / \mathrm{S}$ quotient 
Table 4 Factor loadings of food groups for the three convenience-based food patterns derived by exploratory factor analysis in a representative sample of 13131 German households with food purchase data from 2011

\begin{tabular}{|c|c|c|c|c|c|}
\hline \multicolumn{2}{|l|}{ Food group } & Example foods & Low-convenience & Semi-convenience & Ready-to-eat \\
\hline \multicolumn{6}{|c|}{ First convenience category $(\mathrm{Cl})$} \\
\hline \multirow[t]{2}{*}{ Cereals } & Cla & Kernels, corn & 0.19 & -0.02 & -0.04 \\
\hline & Clb & Flour & 0.60 & 0.26 & -0.32 \\
\hline Potatoes & Cla & Raw potatoes & 0.64 & $0 \cdot 10$ & 0.21 \\
\hline Sugar \& Sweets & Clb & Sugar, chocolate coating & 0.62 & $0 \cdot 18$ & $-0 \cdot 18$ \\
\hline Vegetables & Cla & Raw vegetables & 0.75 & $0 \cdot 10$ & 0.13 \\
\hline Fruits & Cla & Raw fruits & 0.69 & -0.01 & 0.23 \\
\hline Meat & Cla & Raw meat & 0.63 & 0.35 & 0.11 \\
\hline Fish & Cla & Raw fish & 0.32 & -0.20 & 0.11 \\
\hline Dairy & Clb & Sour cream, crème fraîche & 0.66 & 0.19 & -0.15 \\
\hline Eggs & Cla & Eggs & 0.66 & $0 \cdot 19$ & 0.09 \\
\hline Fats \& Oils & $\mathrm{Clb}$ & Vegetable oils cooking fats & 0.54 & 0.36 & $-0 \cdot 13$ \\
\hline Other & $\mathrm{Clb}$ & Salt, herbs, baking powder & 0.48 & 0.23 & -0.01 \\
\hline \multicolumn{6}{|c|}{ Second convenience category (CII) } \\
\hline \multirow[t]{3}{*}{ Cereals } & Cllc & Chilled or dried pasta, instant rice & 0.36 & 0.68 & -0.07 \\
\hline & Clld & Cake and bread baking mixes & 0.24 & 0.36 & -0.04 \\
\hline & Clle & Frozen dumplings, frozen bread for baking & $0 \cdot 16$ & 0.47 & 0.19 \\
\hline \multirow[t]{2}{*}{ Potatoes } & Clld & Dried mashed potatoes & 0.17 & 0.43 & 0.17 \\
\hline & Clle & Frozen French fries, frozen stuffed potatoes & 0.19 & 0.65 & 0.06 \\
\hline Sugar \& Sweets & Clld & Custard powder, dessert powder & 0.18 & 0.08 & -0.06 \\
\hline \multirow{2}{*}{ Vegetables } & Cllc & Frozen, canned or dried vegetables & 0.52 & $0 \cdot 15$ & 0.15 \\
\hline & Clle & Chilled vegetables seasoned or with sauce & 0.58 & 0.36 & 0.30 \\
\hline Fruits & Cllc & Frozen, canned or dried fruits & 0.19 & 0.33 & 0.27 \\
\hline \multirow[t]{2}{*}{ Meat } & Cllc & Chilled or frozen meat, not seasoned & 0.23 & 0.55 & 0.24 \\
\hline & Clle & Hamburger patties, meat loafs & 0.00 & 0.14 & 0.52 \\
\hline \multirow[t]{2}{*}{ Fish } & Cllc & Frozen fish or fish fillets & 0.40 & 0.07 & 0.06 \\
\hline & Clle & Fish fingers, floured or breaded frozen fish & $0 \cdot 16$ & 0.49 & 0.20 \\
\hline Other & Clld & Bouillon cubes, dehydrated sauce mixes & 0.28 & 0.62 & 0.01 \\
\hline \multicolumn{6}{|c|}{ Third convenience category (CIII) } \\
\hline \multirow[t]{3}{*}{ Cereals } & Clllf & Chilled pasta and rice dishes & -0.07 & 0.43 & 0.36 \\
\hline & Clllg & Cake, cookies & 0.39 & $0 \cdot 30$ & 0.37 \\
\hline & Clllh & Bread, rolls & 0.60 & 0.25 & 0.29 \\
\hline \multirow[t]{3}{*}{ Potatoes } & Clllf & Canned potato soup & -0.08 & 0.09 & 0.42 \\
\hline & Clllg & Potato chips & 0.03 & 0.59 & 0.01 \\
\hline & Clllh & Potato salad & 0.04 & 0.09 & 0.48 \\
\hline \multirow[t]{2}{*}{ Sugar \& Sweets } & Clllg & Tiramisu, chocolate, candy & 0.30 & 0.52 & 0.32 \\
\hline & Clllh & Jam, honey & 0.34 & 0.30 & 0.23 \\
\hline \multirow{2}{*}{ Vegetables } & Clllf & Canned vegetable soups and stews & $0 \cdot 10$ & 0.22 & 0.59 \\
\hline & Clllh & Stuffed olives, stuffed peppers & 0.27 & 0.18 & 0.27 \\
\hline Fruits & Clllh & Ready-to-eat fruits & 0.14 & -0.05 & 0.19 \\
\hline \multirow{2}{*}{ Meat } & Clllf & Chilled, canned or frozen meat dishes & 0.02 & 0.49 & 0.46 \\
\hline & Clllh & Sausage, ham & 0.57 & 0.40 & 0.30 \\
\hline \multirow[t]{2}{*}{ Fish } & Clllf & Canned fish soup, frozen fish dinner & 0.00 & 0.28 & 0.14 \\
\hline & Clllh & Smoked salmon, fish salads, tinned fish & 0.51 & -0.05 & 0.42 \\
\hline \multirow[t]{3}{*}{ Dairy } & Clllf & Canned cheese soup & -0.03 & 0.51 & 0.03 \\
\hline & Clllg & Plain and flavoured yoghurt, fruit curd & 0.43 & 0.35 & 0.23 \\
\hline & Clllh & Cheese, tzatziki, herb curd & 0.58 & 0.27 & 0.26 \\
\hline Eggs & Clllh & Egg salad & 0.04 & 0.05 & 0.29 \\
\hline Fats \& Oils & Clllh & Butter, margarine, lard & 0.64 & 0.26 & 0.19 \\
\hline Other & Clllh & Ketchup, custard, spiced sauces & 0.37 & 0.55 & 0.19 \\
\hline \multicolumn{3}{|c|}{$\begin{array}{l}\text { Explained variance (\%) } \\
\text { Total explained variance (\%) }\end{array}$} & $25 \cdot 02$ & $\begin{array}{l}6 \cdot 24 \\
35 \cdot 36\end{array}$ & $4 \cdot 10$ \\
\hline
\end{tabular}

and the pattern score was positive, indicating that a higher adherence to the semi-convenience food pattern resulted in a more beneficial fat composition. Salt density increased with stronger adherence to this pattern, but no significant correlation was found for the percentage of energy from sugar.

While the previously described patterns were either mostly positively or negatively associated with the households' nutrient purchases, the results for the readyto-eat food pattern were mixed. Compared with the other patterns, the correlation coefficients for the ready-to-eat food pattern were relatively low. In particular, although the nutrient density for vitamin D was positively correlated with this food pattern score, lower or negligible positive correlations were detected for vitamin $\mathrm{B}_{12}$, vitamin $\mathrm{C}, \mathrm{Mg}$, $\mathrm{Fe}$ and folate. The remaining micronutrients (vitamin $\mathrm{E}$, $\mathrm{Ca}$, iodide and fluoride) had negligible or negative associations with this food pattern. In addition, the mean energy density was negatively associated with this pattern score, indicating that households more oriented towards the ready-to-eat pattern had a more beneficial diet composition in terms of energy density. However, the 
Table 5 Nutrient and energy densities in quintiles of food pattern scores in a representative sample of 13131 German households with food purchase data from 2011

\begin{tabular}{|c|c|c|c|c|c|c|c|c|c|c|}
\hline & \multirow[b]{2}{*}{ Units } & \multicolumn{2}{|c|}{ Q1 } & \multicolumn{2}{|c|}{ Q3 } & \multicolumn{2}{|c|}{ Q5 } & \multirow[b]{2}{*}{$P$ for trend } & \multicolumn{2}{|c|}{ Correlation analysis } \\
\hline & & Mean† & SE & Mean† & SE & Mean† & SE & & Coefficient & $P$ value \\
\hline \multicolumn{11}{|l|}{ Low-convenience } \\
\hline Vitamin D & $\mu \mathrm{g} / 4184 \mathrm{~kJ} \S$ & 0.016 & 0.000 & 0.017 & 0.000 & 0.018 & 0.000 & $<0.001$ & 0.162 & $<0.001$ \\
\hline Vitamin E & $\mu \mathrm{g} / 4184 \mathrm{~kJ}$ & 48.159 & 0.724 & 52.957 & 0.354 & 53.892 & 0.542 & $<0.001$ & 0.056 & $<0.001$ \\
\hline Folate & $\mu \mathrm{g} / 4184 \mathrm{~kJ}$ & 0.964 & 0.010 & 1.006 & 0.006 & 1.082 & 0.012 & $<0.001$ & 0.123 & $<0.001$ \\
\hline Vitamin $\mathrm{B}_{12}$ & $\mu \mathrm{g} / 4184 \mathrm{~kJ}$ & 0.030 & 0.001 & 0.028 & 0.000 & 0.030 & 0.001 & $<0.001$ & 0.058 & $<0.001$ \\
\hline Vitamin C & $\mu \mathrm{g} / 4184 \mathrm{~kJ}$ & 368.517 & $8 \cdot 265$ & $415 \cdot 467$ & 3.957 & 476.619 & $5 \cdot 870$ & $<0.001$ & 0.162 & $<0.001$ \\
\hline $\mathrm{Ca}$ & $\mathrm{mg} / 4184 \mathrm{~kJ}$ & 4.099 & 0.050 & 3.917 & 0.022 & 3.738 & 0.036 & $<0.001$ & -0.115 & $<0.001$ \\
\hline $\mathrm{Mg}$ & $\mathrm{mg} / 4184 \mathrm{~kJ}$ & 1.387 & 0.010 & 1.366 & 0.005 & 1.378 & 0.010 & $<0.01$ & -0.017 & $<0.05$ \\
\hline $\mathrm{Fe}$ & $\mu \mathrm{g} / 4184 \mathrm{~kJ}$ & 66.491 & 1.029 & $66 \cdot 522$ & 0.797 & $66 \cdot 108$ & 0.600 & $>0.1$ & 0.017 & $<0.1$ \\
\hline lodide & $\mu \mathrm{g} / 4184 \mathrm{~kJ}$ & 0.619 & 0.028 & 0.611 & 0.007 & 0.704 & 0.011 & $<0.001$ & 0.065 & $<0.001$ \\
\hline Fluoride & $\mu \mathrm{g} / 4184 \mathrm{~kJ}$ & 6.513 & 0.479 & $6 \cdot 767$ & 0.126 & $8 \cdot 324$ & 0.176 & $<0.001$ & 0.065 & $<0.001$ \\
\hline Energy & $\mathrm{kJ} / 100 \mathrm{~g}$ & $750 \cdot 295$ & 5.009 & 709.966 & $2 \cdot 381$ & 678.419 & 3.674 & $<0.001$ & -0.184 & $<0.001$ \\
\hline Energy & $\mathrm{kcal} / 100 \mathrm{~g}$ & $179 \cdot 325$ & $1 \cdot 197$ & 169.686 & 0.569 & $162 \cdot 146$ & 0.878 & $<0.001$ & -0.184 & $<0.001$ \\
\hline P/S quotientł & - & 0.348 & 0.007 & 0.335 & 0.002 & 0.341 & 0.004 & $<0.05$ & -0.034 & $<0.01$ \\
\hline Sugar & $\%$ of energy & 0.108 & 0.002 & 0.112 & 0.001 & 0.116 & 0.001 & $<0.001$ & 0.050 & $<0.001$ \\
\hline Salt & $\mathrm{g} / 4184 \mathrm{~kJ}$ & 4.263 & 0.123 & 4.259 & 0.042 & 4.476 & 0.058 & $<0.001$ & 0.052 & $<0.001$ \\
\hline \multicolumn{11}{|c|}{ Semi-convenience } \\
\hline Vitamin D & $\mu \mathrm{g} / 4184 \mathrm{~kJ}$ & 0.021 & 0.001 & 0.017 & 0.000 & 0.015 & 0.000 & $<0.001$ & -0.262 & $<0.001$ \\
\hline Vitamin $\mathrm{E}$ & $\mu \mathrm{g} / 4184 \mathrm{~kJ}$ & 50.603 & 0.720 & 51.369 & 0.406 & 50.469 & 0.420 & $>0.1$ & -0.017 & $<0.05$ \\
\hline Folate & $\mu \mathrm{g} / 4184 \mathrm{~kJ}$ & $1 \cdot 181$ & 0.014 & 0.970 & 0.005 & 0.907 & 0.008 & $<0.001$ & -0.240 & $<0.001$ \\
\hline Vitamin $B_{12}$ & $\mu \mathrm{g} / 4184 \mathrm{~kJ}$ & 0.033 & 0.001 & 0.028 & 0.000 & 0.027 & 0.000 & $<0.001$ & -0.165 & $<0.001$ \\
\hline Vitamin C & $\mu \mathrm{g} / 4184 \mathrm{~kJ}$ & 541.815 & $12 \cdot 161$ & 385.608 & 3.169 & 338.481 & 5.536 & $<0.001$ & -0.245 & $<0.001$ \\
\hline $\mathrm{Ca}$ & $\mathrm{mg} / 4184 \mathrm{~kJ}$ & 4.236 & 0.067 & 3.890 & 0.021 & 3.644 & 0.033 & $<0.001$ & -0.086 & $<0.001$ \\
\hline $\mathrm{Mg}$ & $\mathrm{mg} / 4184 \mathrm{~kJ}$ & 1.496 & 0.017 & 1.349 & 0.005 & 1.304 & 0.007 & $<0.001$ & -0.194 & $<0.001$ \\
\hline $\mathrm{Fe}$ & $\mu \mathrm{g} / 4184 \mathrm{~kJ}$ & 69.510 & 1.361 & 65.504 & 0.526 & 65.862 & 1.343 & $<0.001$ & -0.083 & $<0.001$ \\
\hline lodide & $\mu \mathrm{g} / 4184 \mathrm{~kJ}$ & 0.655 & 0.029 & 0.622 & 0.008 & 0.606 & 0.010 & $<0.001$ & -0.035 & $<0.001$ \\
\hline Fluoride & $\mu \mathrm{g} / 4184 \mathrm{~kJ}$ & 7.494 & 0.549 & 6.927 & 0.133 & $6 \cdot 642$ & 0.176 & 0.001 & -0.024 & $<0.01$ \\
\hline Energy & $\mathrm{kJ} / 100 \mathrm{~g}$ & 671.230 & $6 \cdot 181$ & $722 \cdot 798$ & 2.373 & 750.499 & 3.823 & $<0.001$ & 0.205 & $<0.001$ \\
\hline Energy & $\mathrm{kcal} / 100 \mathrm{~g}$ & $160 \cdot 428$ & 1.477 & 172.753 & 0.567 & $179 \cdot 374$ & 0.914 & $<0.001$ & 0.205 & $<0.001$ \\
\hline $\mathrm{P} / \mathrm{S}$ quotient & - & 0.336 & 0.007 & 0.330 & 0.002 & 0.345 & 0.003 & 0.001 & 0.027 & $<0.01$ \\
\hline Sugar & $\%$ of energy & 0.108 & 0.002 & 0.116 & 0.001 & 0.109 & 0.001 & $>0.1$ & -0.012 & $>0.1$ \\
\hline Salt & $\mathrm{g} / 4184 \mathrm{~kJ}$ & $4 \cdot 313$ & 0.133 & $4 \cdot 346$ & 0.070 & $4 \cdot 341$ & 0.086 & $<0.001$ & -0.041 & $<0.001$ \\
\hline \multicolumn{11}{|l|}{ Ready-to-eat } \\
\hline Vitamin D & $\mu \mathrm{g} / 4184 \mathrm{~kJ}$ & 0.014 & 0.000 & 0.017 & 0.000 & 0.020 & 0.000 & $<0.001$ & 0.212 & $<0.001$ \\
\hline Vitamin E & $\mu \mathrm{g} / 4184 \mathrm{~kJ}$ & $55 \cdot 301$ & 0.534 & 51.081 & 0.313 & $49 \cdot 190$ & 0.286 & $<0.001$ & -0.084 & $<0.001$ \\
\hline Folate & $\mu \mathrm{g} / 4184 \mathrm{~kJ}$ & 0.960 & 0.006 & 1.014 & 0.005 & 0.985 & 0.005 & $<0.001$ & 0.022 & $<0.05$ \\
\hline Vitamin $B_{12}$ & $\mu \mathrm{g} / 4184 \mathrm{~kJ}$ & 0.026 & 0.000 & 0.029 & 0.000 & 0.030 & 0.000 & $<0.001$ & 0.106 & $<0.001$ \\
\hline Vitamin C & $\mu \mathrm{g} / 4184 \mathrm{~kJ}$ & 367.699 & $3 \cdot 871$ & $422 \cdot 111$ & $3 \cdot 712$ & 409.438 & 3.762 & $<0.001$ & 0.057 & $<0.001$ \\
\hline $\mathrm{Ca}$ & $\mathrm{mg} / 4184 \mathrm{~kJ}$ & 3.769 & 0.025 & 3.939 & 0.020 & 3.828 & 0.022 & $<0.05$ & -0.037 & $<0.001$ \\
\hline $\mathrm{Mg}$ & $\mathrm{mg} / 4184 \mathrm{~kJ}$ & 1.291 & 0.006 & 1.376 & 0.005 & 1.376 & 0.005 & $<0.001$ & 0.078 & $<0.001$ \\
\hline $\mathrm{Fe}$ & $\mu \mathrm{g} / 4184 \mathrm{~kJ}$ & 61.925 & 0.654 & $66 \cdot 356$ & 0.493 & 65.477 & 0.430 & $<0.001$ & 0.041 & $<0.001$ \\
\hline lodide & $\mu \mathrm{g} / 4184 \mathrm{~kJ}$ & 0.704 & 0.013 & 0.616 & 0.007 & 0.578 & 0.006 & $<0.001$ & -0.058 & $<0.001$ \\
\hline Fluoride & $\mu \mathrm{g} / 4184 \mathrm{~kJ}$ & $8 \cdot 375$ & 0.228 & $6 \cdot 812$ & 0.127 & $6 \cdot 118$ & 0.099 & $<0.001$ & -0.053 & $<0.001$ \\
\hline Energy & $\mathrm{kJ} / 100 \mathrm{~g}$ & 741.722 & 2.981 & $710 \cdot 172$ & $2 \cdot 322$ & 704.713 & 2.477 & $<0.001$ & -0.095 & $<0.001$ \\
\hline Energy & $\mathrm{kcal} / 100 \mathrm{~g}$ & $177 \cdot 276$ & 0.712 & 169.735 & 0.555 & 168.430 & 0.592 & $<0.001$ & -0.095 & $<0.001$ \\
\hline $\mathrm{P} / \mathrm{S}$ quotientł & - & 0.344 & 0.003 & 0.328 & 0.002 & 0.339 & 0.002 & $>0.1$ & -0.007 & $>0.1$ \\
\hline Sugar & $\%$ of energy & 0.120 & 0.001 & 0.112 & 0.001 & 0.112 & 0.001 & $<0.001$ & -0.026 & $<0.01$ \\
\hline Salt & $\mathrm{g} / 4184 \mathrm{~kJ}$ & 4.365 & 0.066 & 4.237 & 0.039 & 4.351 & 0.040 & $<0.001$ & 0.033 & $<0.001$ \\
\hline
\end{tabular}

†Adjusted for age and household size.

†Ratio of PUFA to SFA.

$\S 4184 \mathrm{~kJ}=1000 \mathrm{kcal}$.

correlation was not as strong as the correlation between the low-convenience food pattern and mean energy density. No significant association was detected for the $\mathrm{P} / \mathrm{S}$ quotient. The density of salt was positively correlated with this pattern score whereas the percentage of energy from sugar was negatively associated.

\section{Food patterns and bousebold characteristics}

Table 6 shows the results of the regression analysis for the three patterns. Whereas household income was significantly associated with the first two pattern scores, it was not for the ready-to-eat pattern. The significance of the quadratic term revealed that as income increased, adherence to the low-convenience and semi-convenience food patterns increased at lower rates. The higher coefficient for the low-convenience food pattern indicated that households with a higher adherence to this pattern had a higher income. Household size and composition also showed many significant associations with the first two pattern scores. Household size was positively associated with both scores but the coefficient for the semiconvenience score was higher. Single-person households 
Table 6 Household characteristics associated with convenience-based food pattern scores derived by exploratory factor analysis in a representative sample of 13131 German households with food purchase data from 2011

\begin{tabular}{|c|c|c|c|}
\hline & Low-convenience & Semi-convenience & Ready-to-eat \\
\hline Variable & Coefficient & Coefficient & Coefficient \\
\hline \multicolumn{4}{|l|}{ Variables referring to the whole household } \\
\hline Household income & $0 \cdot 127^{\star \star *}$ & $0.079^{*}$ & -0.021 \\
\hline Squared household income & $-0.022^{\star \star *}$ & $-0.018^{\star *}$ & 0.000 \\
\hline No. of persons in the household & $0.196^{\star \star *}$ & $0.387^{\star \star \star}$ & -0.020 \\
\hline \multicolumn{4}{|l|}{ Reference $=$ multi-person household } \\
\hline Single household, male & $-0.585^{\star \star *}$ & $0 \cdot 186^{\star \star \star}$ & $0.129^{\star \star}$ \\
\hline Single household, female & $-0.532^{\star \star *}$ & $0 \cdot 146^{\star * *}$ & $-0 \cdot 301^{\star \star *}$ \\
\hline No. of children aged $0-6$ years & $-0.238^{\star \star *}$ & $-0.260^{\star \star *}$ & -0.046 \\
\hline No. of children aged $7-13$ years & $-0.171^{\star \star \star}$ & $0.089^{\star \star \star}$ & -0.032 \\
\hline No. of children aged $14-17$ years & $-0.168^{\star \star \star}$ & $0.291^{* * *}$ & -0.070 \\
\hline \multicolumn{4}{|l|}{ Variables referring to the head of the household } \\
\hline \multicolumn{4}{|l|}{ Reference $=$ medium education } \\
\hline Lower education & 0.006 & $0.131^{\star \star *}$ & $-0.074^{\star *}$ \\
\hline Higher education & $0.047^{*}$ & $-0.045^{\star}$ & 0.028 \\
\hline \multicolumn{4}{|c|}{ Variables referring to the person responsible for the food purchases } \\
\hline 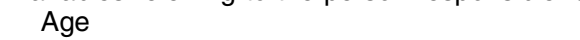 & $0.022^{\star \star \star}$ & $-0.010^{\star \star \star}$ & $0.014^{\star \star \star}$ \\
\hline \multicolumn{4}{|l|}{ Reference $=$ not active in the labour market } \\
\hline Working part-time & $-0.052^{*}$ & 0.037 & -0.011 \\
\hline Working full-time & $-0.156^{\star \star \star}$ & -0.038 & $0.096^{\star *}$ \\
\hline \multicolumn{4}{|l|}{ Reference $=$ low price awareness } \\
\hline High price awareness & $0.040^{*}$ & $0 \cdot 145^{\star \star \star}$ & 0.024 \\
\hline Oriented towards dietary guidelines $\dagger$ & $0 \cdot 109^{* * *}$ & $-0.113^{\star \star *}$ & $-0.065^{\star \star *}$ \\
\hline Oriented towards supplements/fortified foods $†$ & $-0.126^{\star \star *}$ & $0.046^{\star \star \star}$ & $0 \cdot 121^{\star \star \star}$ \\
\hline Constant & $-1.446^{\star \star \star}$ & $-0.513^{\star \star \star}$ & $-0.560^{\star \star \star}$ \\
\hline$R^{2}$ (adjusted) & 0.2853 & 0.3181 & 0.0658 \\
\hline
\end{tabular}

${ }^{*} P<0.05,{ }^{* *} P<0.01,{ }^{* * *} P<0.001$.

†Factor score resulted from the factor analysis shown in the online supplementary material, Supplemental Table 1.

and those including children over 7 years old had a negative association with the low-convenience food pattern, but these variables were positively correlated with the semi-convenience food pattern. Whereas households with a higher adherence to the low-convenience food pattern had a higher education, those with a higher adherence to the semi-convenience food pattern were less well educated. Age was positively associated with the semi-convenience food pattern score but showed negative correlations with the low-convenience score. Working part- or full-time was negatively associated with the lowconvenience food pattern and showed no significant correlation with the semi-convenience food pattern. Both patterns were shown to have high price awareness, but the coefficient was more pronounced for the semiconvenience food pattern, indicating that this awareness was higher in these households. Households with a stricter adherence to the low-convenience food pattern stated that they were aware of health and sustainability, and at the same time rejected supplements and fortified foods. In contrast, households with a stronger adherence to the semi-convenience food pattern stated the reverse. Whereas many of the included variables were significantly associated with the low-convenience and semiconvenience food patterns, fewer of the variables were correlated with the ready-to-eat pattern. For this pattern, significant positive associations were detected with single males, age and working full-time, while significant negative correlations were observed with single females and a lower education level. Similar to the semi-convenience pattern, these households reported that they had lower awareness of health and sustainability and preferred supplements and fortified foods.

\section{Discussion}

The present study aimed at identifying food purchase patterns with explicit reference to their convenience level for the first time. Previous dietary pattern analyses have focused primarily on health aspects. The convenience aspect was only partially and indirectly considered, by including processed foods such as hamburger or pizza in the analyses. However, focusing on convenience implies an explicit consideration of, among others, time and culinary skills needed for food preparation. Because there was no food classification considering all aspects of convenience, a new classification scheme, the CFCS, was developed in the present study. On the basis of this classification scheme new food purchase patterns were identified using factor analysis and a representative sample of German households. Subsequently, both the nutrient and energy densities of the patterns and household characteristics associated with the patterns were analysed. 
Overall, three food purchase patterns were found: a low-convenience food pattern, a semi-convenience food pattern and a ready-to-eat food pattern. Two of the three identified patterns were characterized by higher purchases of foods of the second and third convenience categories. This indicates that convenience foods are an essential part of German households' consumption habits. Even in the pattern termed 'low-convenience', which consisted mainly of foods that require extensive preparation in the household, some foods were found in their convenience form, although they are also available in an unprocessed form (e.g. frozen fish instead of fresh fish). An explanation could be that processing fresh fish is relatively time-consuming and/or requires special skills. However, another reason could be that fresh fish is less available on the market compared with foods such as fresh fruits and vegetables.

The analysis of nutrient densities of the products as purchased revealed that adherence to the low-convenience food pattern resulted in mainly positive effects for the densities of energy and nutrients, whereas a preference for the semi-convenience food pattern was associated with lower nutrient and higher energy densities. This is in line with findings of previous studies that found that many convenience foods have lower nutritional quality ${ }^{(9-11,21,22)}$.

However, it is particularly interesting that a higher adherence to the ready-to-eat pattern was associated with a more beneficial diet composition in terms of energy than the semi-convenience pattern. This shows that purchasing ready-to-eat products does not necessarily lead to a higher energy density when it is combined with foods that are low in energy. In the ready-to-eat pattern group, the factor loadings for low-energy foods such as fresh fruits and vegetables were - albeit below the threshold of 0.4 - clearly higher than were those observed for the semi-convenience food pattern. Additionally, the factor loadings for the energy-dense sugar and sweets group were clearly lower than were those for the semi-convenience food pattern.

Another interesting aspect is that the semi-convenience food pattern was the only pattern for which a positive association with the $\mathrm{P} / \mathrm{S}$ quotient was found. A possible explanation could be that, in comparison with the other food pattern groups, these households choose low-fat or fat-reduced products and margarine instead of butter. However, because this analysis considered the fats and oil group as a whole and did not distinguish between foods with different fat contents, this aspect could not be further analysed herein. In future studies, an additional classification based on foods' fat contents could be added to gain a deeper insight into the association between food patterns and the $\mathrm{P} / \mathrm{S}$ quotient.

Interestingly, all pattern scores were positively associated with salt density, meaning that higher adherence to each pattern was associated with a higher salt consumption. For the semi-convenience and ready-to-eat patterns, this could be explained by the high salt content present in processed foods. Studies assessing the salt content of different convenience products and ready-made meals found many of those products have salt contents that exceed the recommendations ${ }^{(30,43)}$. The increasing salt density of the low-convenience pattern was surprising at first glance. However, one explanation could be that a large part of the salt is used in cooking water that is usually poured away with the water and therefore is not consumed by the household. Hence, the salt densities for all patterns - but especially for the low-convenience pattern could be overestimated. Percentage of energy from sugar showed a positive correlation with the low-convenience pattern and a negative correlation with the ready-to-eat pattern. One explanation for this might be that households of the low-convenience pattern use sugar when preparing or sweetening foods rather than artificial sweeteners, which are probably more often used by households of the other two patterns.

The analysis of the associations between household characteristics and the food pattern scores showed many significant influences. The low-convenience food pattern was preferred by multi-person households consisting of adults, and adherence to this pattern was associated with higher income, higher age and higher education level. In addition, the person responsible for food purchases was less likely to work full- or part-time. The semi-convenience food pattern was preferred by single-person households of both sexes and by households with (pre)adolescents and a lower education level. The ready-to-eat food pattern was preferred mainly by male single households, in households in which the person responsible for food purchases worked full-time and households with a medium education level. Overall, the first two patterns could be relatively well explained by the included variables, as shown by the adjusted $R^{2}$ values of 0.28 and 0.32 , respectively. In contrast, the adjusted $R^{2}$ of the ready-to-eat pattern was only $0 \cdot 07$, indicating that many additional variables are responsible for adherence to this pattern. However, in general, it can be summarized that socio-economic status, household composition and time available for meal preparation played an important role in convenience purchase habits. While households with a higher socioeconomic status were more likely to consume healthier diets consisting mainly of fresh foods, a lower socioeconomic status was associated with purchases of convenience variants that required less preparation time and fewer cooking skills.

Interestingly, the purchase habits were well reflected in the attitude statements of the person responsible for the food purchases. Whereas households with a higher adherence to the low-convenience pattern stated that they were aware of health and sustainability but did not prefer supplements and fortified foods, households adhering to the other two patterns stated the opposite. Obviously, the personal statements collected are meaningful indicators of the purchases of convenience foods. Those households who buy many fresh food variants, which are often 
healthier and climate friendlier because of their lower greenhouse gas emissions ${ }^{(44)}$, stated that they paid more attention to such factors. It is also interesting that paying attention to the healthiness of foods and considering their sustainability seem to be closely related, as they load on one factor. Some households obviously pay more attention than others to food consumption and nutritional aspects in general.

The present study focused mainly on the convenience aspect of food purchases, and a major finding was that the time available for meal preparation played an important role in households deciding whether to prepare a meal from scratch or to buy processed or ready-to-eat alternatives. Households in which the person responsible for food purchases did not work full- or part-time had a stronger preference for the low-convenience food pattern, whereas working full-time was associated with the readyto-eat pattern. This finding is in line with those of previous studies that identified available leisure time (or a lack of it) as a principal driver of the consumption of ready-to-eat foods ${ }^{(39,45)}$. Sheely assumed that by buying convenience foods households buy time (by not having to prepare a meal from scratch at home) and therefore are less price sensitive when buying those foods ${ }^{(46)}$. This assumption is supported by our results indicating that whereas the lowconvenience and the semi-convenience food pattern groups were price conscious, the price awareness variable was not significant in the ready-to-eat pattern. Interestingly, the semi-convenience food pattern was not related to working part-time or full-time. Although this pattern consists only of food groups that require little preparation time, time constraints seem unrelated to the pattern. This confirms findings of previous studies which found that there are groups of households that use convenience foods simply because they are quick and easy to prepare without any need to save time ${ }^{(4,38,39)}$. A lack of cooking skills could be the reason why these households prefer these foods.

The results also indicated that preparation time or time spent for cooking was associated with age. A higher age was related to the low-convenience pattern and thus to lower consumption of highly processed foods. As Brunner et al., who observed the same association, argue, this could be because as people get older and eventually enter retirement, they have more time for cooking and no need for time-saving convenience products ${ }^{(4)}$. Another reason might be that older households are less familiar with convenience products because these products were not available to the extent they are today when their cooking habits were formed ${ }^{(4,7)}$. The association between higher age and more time spent for cooking was also reflected in the household composition variables: the low-convenience pattern was associated with increasing household size but not with the presence of children, which indicates that the pattern is mainly preferred by older couples.

Household composition variables, namely household size and presence of children aged 7 years or older, were also associated with the semi-convenience pattern. This seems plausible as cooking a meal from scratch, although there are economies of scale, requires more time as more members are present in the household. Therefore, choosing processed foods that require less preparation is especially tempting for larger households. More leisure activities, different school and work patterns cause shared family meals to become a rarity and thus increase the demand for foods that can quickly and easily be prepared ${ }^{(38)}$. However, not all variables measuring the presence of children were positively associated with the semiconvenience pattern. The presence of children up to 6 years of age was negatively associated with the pattern. This might be because for parents of younger children providing homemade food is seen as very important for their health ${ }^{(38)}$. As children grow older they also develop their own preferences, which are often preferences for convenience foods such as French fries.

Previous work indicated that young households and single households have a preference for convenience foods and are interested in easy-to-prepare meals ${ }^{(3,6,7)}$. The present study is in line with these findings. Both single variables were positively associated with the semiconvenience pattern. For the ready-to-eat pattern, only the male single dummy showed a positive association. This is also in line with previous findings which indicated that ready-made meals are consumed mostly by men ${ }^{(41,47)}$.

The present study used household purchase data to identify food patterns. As in such data households are not asked directly about their dietary habits, as is the case with intake data, it can be assumed that they are less biased by systematic over- and under-reporting. Furthermore, the very detailed documentation of households' food purchases allowed a precise assignment of each product to the individual levels of convenience.

However, the data also have some limitations. First, out-of-home consumption purchases are not included and therefore the measured diet quality refers exclusively to in-home purchases which account for $77 \%$ of all food expenses in Germany ${ }^{(48)}$. However, as foods purchased out of home are more expensive than those purchased for in-home consumption, it can be expected that the share of quantitative food consumption considered in our study is higher than $77 \%$. Second, the data display the food purchase habits with regard to the whole household. Hence, the results should not be used for drawing conclusions about individuals. Third, food purchases differ from food intakes because of waste. A UK study found that approximately $20 \%$ of all purchases were thrown away by households ${ }^{(49)}$. This amount refers to avoidable and unavoidable kitchen waste. As the BLS includes information on nutrients for foods with and without inedible kitchen waste, it was possible to link the respective processing form to the purchase data (e.g. potatoes peeled or unpeeled). Therefore, the difference between nutrients purchased and actually consumed refers to the part of the 
waste that could be avoided by the households. It has to be noted that, as the entire purchases were recorded, we had the information of all ingredients used to prepare a meal. Therefore, overall, the purchased nutrients differ from the actually consumed nutrients in the edible parts of foods that were thrown away by the households and in the parts that get lost because of cooking techniques (e.g. boiling or steaming). As there is a difference between purchase and intake, the results should be interpreted only in terms of purchases.

Finally, it has to be noted that the level of convenience can vary for some products and they therefore could have been assigned to another convenience level compared with the actual use in the household. This could be the case for products such as Gouda cheese, which is normally eaten as purchased and therefore is part of convenience group CIIIh. However, Gouda cheese could also be grated and used on pizza. In this case it belongs to the convenience group CIb. Because households did not report how a food was used, these foods were assigned to the convenience level they are commonly used for.

\section{Summary and conclusion}

The present study identified food purchase patterns in a representative population of German households using food groups classified based on the developed CFCS. Three patterns were identified: a low-convenience, a semiconvenience and a ready-to-eat food pattern. It was shown in particular that a higher adherence to the semiconvenience pattern, mainly consisting of foods that are easy to prepare in combination with ready-made meals, sweets and salty snacks, resulted in lower nutrient and higher energy densities. A preference for this pattern was associated with being younger, lower educated and having children aged 7 years or older. Furthermore, the results indicated that households having a higher preference for the semi-convenience pattern showed little interest in health and sustainable aspects of food consumption, whereas households with a higher preference for lowconvenience foods had a higher interest in these factors. Interestingly, the semi-convenience pattern was the only one in which no association with work participation of the person responsible for the food purchases was observed. An explanation could be that not time constraints but rather a lack of cooking skills is the reason why these households prefer mainly processed foods. Therefore, interventions targeted on enhancing cooking skills could be an effective strategy to increase incentives for buying more unprocessed foods, which, in turn, could improve the nutritional quality of the diet ${ }^{(41,50)}$. However, as these households have little interest in health and sustainable aspects of food consumption it is a great challenge to reach this population group. Nutrition and consumer education in schools, especially directed towards lower education groups, could be one way to strengthen awareness of the nutritional values of processed and unprocessed foods and to improve cooking skills ${ }^{(51)}$. However, for households with a higher adherence to the ready-to-eat pattern, time constraints seem to play an important role when making food consumption decisions. This pattern was associated with working full-time, being a single male and a medium education level. Hence, in addition to an enlargement of cooking skills, it is important for these households to have access to healthy convenience foods. Already at present the market offers a growing number of healthy convenience products such as ready-to-eat fruits and vegetables which could be used to substitute less healthy snacks. However, as these households too showed little interest in health and sustainable aspects of food consumption, appropriate school education programmes could also help these households to improve their dietary quality. An increased awareness for healthy diet across a broad range of the population could, in turn, encourage the food industry to further improve the nutritional quality of convenience foods.

\section{Acknowledgements}

Financial support: This research received no specific grant from any funding agency in the public, commercial or notfor-profit sectors. Conflict of interest: The authors declare that there is no conflict of interest regarding the publication of this paper. Authorship: Planning the design of the analysis: J.P. and S.T. Data preparation: J.P. and S.T. Implementation of the statistical analysis: J.P. Writing and revising the manuscript: J.P. and ST. Ethics of buman subject participation: Not applicable.

\section{Supplementary material}

To view supplementary material for this article, please visit https://doi.org/10.1017/S1368980017003378

\section{References}

1. Scholliers P (2015) Convenience foods. What, why, and when. Appetite 94, 2-6.

2. Jackson P \& Vierhoff V (2016) Reframing convenience food. Appetite 98, 1-11.

3. Candel MJJ (2001) Consumer's convenience orientation towards meal preparation. Conceptualization and measurement. Appetite 35, 15-28.

4. Brunner TA, van der Horst K \& Siegrist M (2010) Convenience food products. Drivers for consumption. Appetite 25, 498-506.

5. Slimani N, Deharveng G, Southgate DA et al. (2009) Contribution of highly industrially processed foods to the nutrient intakes and patterns of middle-aged populations in the European Prospective Investigation into Cancer and Nutrition study. Eur J Clin Nutr 63, Suppl. 4, S206-S225.

6. Harris JM \& Shiptsova R (2007) Consumer demand for convenience foods: demographics and expenditures. J Food Distrib Res 38, 22-36. 
7. Daniels S, Glorieux I, Minnen J et al. (2015) Convenience on the menu? A typological conceptualization of family food expenditures and food-related time patterns. Soc Sci Res $\mathbf{5 1}$ 205-218.

8. Buckley M, Cowan C \& McCarthy M (2007) The convenience food market in Great Britain: convenience food lifestyle (CFL) segments. Appetite 49, 600-617.

9. Anderson A, Wrieden W, Tasker S et al. (2008) Ready meals and nutrient standards: challenges and opportunities. Proc Nutr Soc 67, E223.

10. Remnant J \& Adams J (2015) The nutritional content and cost of supermarket ready-meals. Cross-sectional analysis. Appetite 92, 36-42.

11. Weaver CM, Dwyer J, Fulgoni VL 3rd et al. (2014) Processed foods: contributions to nutrition. Am J Clin Nutr 99, 1525-1542.

12. Van Dam RM, Grievnik L, Ocke MC et al. (2003) Patterns of food consumption and risk factors for cardiovascular disease in the general Dutch population. Am J Clin Nutr 77, 1156-1163.

13. Hamer M \& Mishra GD (2010) Dietary patterns and cardiovascular risk markers in the UK Low Income Diet and Nutrition Survey. Nut Metab Cardiovasc Dis 20, 491-497.

14. Kerver JM, Yang EJ, Bianchi L et al. (2003) Dietary patterns associated with risk factors for cardiovascular disease in healthy US adults. Am J Clin Nutr 78, 1003-1110.

15. Fung TT \& Brown LS (2013) Dietary patterns and the risk of colorectal cancer. Curr Nutr Rep 2, 48-55.

16. Reedy J, Wirfalt E, Flood A et al. (2009) Comparing 3 dietary pattern methods: cluster analysis, factor analysis, and index analysis with colorectal cancer risk. Am J Epidemiol 171, 479-487.

17. Mishra G, Ball K, Arbuckle J et al. (2002) Dietary patterns of Australian adults and their association with socioeconomic status: results from the 1995 National Nutrition Survey. EurJ Clin Nutr 56, 687-693.

18. Ax E, Lemming EW, Becker W et al. (2016) Dietary patterns in Swedish adults; results from a national dietary survey. $\mathrm{BrJ}$ Nutr 115, 95-104

19. Monteiro CA, Levy RB, Claro RM et al. (2010) A new classification of foods based on the extent and purpose of their processing. Cad Saude Publica 26, 2039-2049.

20. Eicher-Miller HA, Fulgoni VL 3rd \& Keast DR (2012) Contributions of processed foods to dietary intake in the US from 2003-2008: a report on the Food and Nutrition Science Solutions Joint Task Force of the Academy of Nutrition and Dietetics, American Society for Nutrition, Institute of Food Technologists, and International Food Information Council. J Nutr 142, issue 11, S2057-S2072.

21. Monteiro CA, Levy RB, Claro RM et al. (2011) Increasing consumption of ultra-processed foods and likely impact on human health: evidence from Brazil. Public Health Nutr 14, 5-13.

22. Moubarac JC, Martins APB, Claro RM et al. (2013) Consumption of ultra-processed foods and likely impact on human health. Evidence from Canada. Public Health Nutr 16, 2240-2248.

23. Steele EM, Popkin BM, Swinburn B et al. (2017) The share of ultra-processed foods and the overall nutritional quality of diets in the US: evidence from a nationally representative cross-sectional study. Popul Health Metr 15, 6.

24. Park JL \& Capps O Jr (1997) Demand for prepared meals by US households. Am J Agric Econ 79, 814-824.

25. Costa AI, Dekker M, Beumer RR et al. (2001) A consumeroriented classification system for home meal replacements. Food Qual Prefer 12, 229-242.

26. Bonke J (1996) Economic influences on food choice - nonconvenience versus convenience food consumption. In Food Choice, Acceptance and Consumption, pp. 293-318
[HL Meiselman and HJH MacFie, editors]. Boston, MA: Springer.

27. Daniels S \& Glorieux I (2015) Convenience, food and family lives. A socio-typological study of household food expenditures in 21st-century Belgium. Appetite 94, 54-61.

28. Pearson JM, Capps O Jr, Gassman C et al. (1985) Degree-of-readiness classifications for systems for foods: development, testing, and use. J Consum Stud Home Econ 9, 133-143.

29. Pepper AW (1980) The relationship between fast foods and convenience-foods definitions and developments. J Consum Stud Home Econ 4, 249-255.

30. Poti JM, Mendez MA, Ng SW et al. (2015) Is the degree of food processing and convenience linked with the nutritional quality of foods purchased by US households? Am J Clin Nutr 101, 1251-1262.

31. Harman HH (1960) Modern Factor Analysis. Chicago, IL and London: The University of Chicago Press.

32. Meyers L (2013) Applied Multivariate Research: Design and Interpretation. Los Angeles, CA: SAGE Publications, Inc.

33. Schulze MB, Hoffmann K \& Boeing H (2003) Risk of hypertension among women in the EPIC-Potsdam study: comparison of relative risk estimates for exploratory and hypothesis-oriented dietary patterns. Am J Epidemiol 158, 365-373.

34. Thurstone LL (1934) The vectors of mind. Psychol Rev 41, $1-32$.

35. Mensink GBM, Fletcher R, Gurinovic M et al. (2013) Mapping micronutrient intake across Europe. Br J Nutr 110, $755-773$

36. Newman C, Henchion M \& Mathews A (2001) A double hurdle model of Irish household expenditure on prepared meals. Appl Econ 35, 1053-1061.

37. Nayga R (1998) A sample selection model for prepared food expenditures. Appl Econ 30, 345-352.

38. Carrigan M, Szmigin I \& Leek S (2006) Managing routine food choices in UK families: the role of convenience consumption. Appetite 47, 372-383.

39. De Boer M, McCarthy M, Cowan C et al. (2004) The influence of lifestyle characteristics and beliefs about convenience foods on the demand for convenience foods in the Irish market. Food Qual Prefer 15, 155-165.

40. Geeroms N, Verbeke W \& Van Konhove P (2008) Consumers' health-related motive orientations and ready meal consumption behavior. Appetite 51, 704-712.

41. Van der Horst K, Brunner TA \& Siegrist M (2011) Readymeal consumption: associations with weight status and cooking skills. Public Health Nutr 14, 239-245.

42. Linting M, Meulman JJ, Groenen PJ et al. (2007) Nonlinear principal components analysis: introduction and application. Psychol Methods 12, 336-358.

43. Kanzler S, Hartmann C, Gruber A et al. (2014) Salt as a public health challenge in continental European convenience and ready meals. Public Health Nutr 17, 2459-2466.

44. Fritsch UR \& Eberle U (2009) Greenhouse-Gas Emissions from the Production and Processing of Foods. Darmstadt: Öko-Institut eV.

45. Cutler DM, Glaeser EL \& Shapiro JM (2003) Why have Americans become more obese? J Econ Perspect 17, 93-118.

46. Sheely M (2008) Global adoption of convenience foods. Am J Agric Econ 90, 1356-1365.

47. Alkerwi A, Crichton GE \& Hébert JR (2015) Consumption of ready-made meals and increased risk of obesity: findings from the Observation of Cardiovascular Risk Factors in Luxembourg (ORISCAV-LUX) study. Br J Nutr 113, $270-277$.

48. Federal Statistical Office, Germany (2011) Einkommensund Verbrauchsstichprobe: Aufwendungen privater 
Haushalte für Nahrungsmittel, Getränke und Tabakwaren (Sample Survey of Income and Expenditure: Housebold Expenditure on Food, Beverages and Tobacco). Wiesbaden: Statistisches Bundesamt.

49. Waste \& Resources Action Programme (2009) Household Food and Drink Waste in the UK. http://www.wrap.org.uk/ sites/files/wrap/Household_food_and_drink_waste_in_the_ UK_-_report.pdf (accessed July 2017).
50. Wrieden WL, Anderson AS, Longbottom PJ et al. (2007) The impact of a community-based food skills intervention on cooking confidence, food preparation methods and dietary choices - an exploratory trial. Public Health Nutr 10, 203-211.

51. Larson NI, Story M, Eisenberg ME et al. (2006) Food preparation and purchasing roles among adolescents: associations with sociodemographic characteristics and diet quality. J Am Diet Assoc 106, 211-218. 